\title{
Analysis of Financial Statements During COVID-19 from the Perspective of Managers_—Case Study Based on TME
}

\author{
Qianyue Chen ${ }^{1, *}$ \\ ${ }^{1}$ Huazhong University of Science and Technology, School of Economics, Wuhan, China, 430070 \\ *Corresponding author. Email: qianyue_chen@126.com
}

\begin{abstract}
With the development of network technology, China's mobile music market has also grown at an amazing speed in recent years. More and more users begin to pay for music works and music services. From the perspective of managers, taking TME group as an example, this paper analyzes the information in its financial statements, especially focusing on what factors caused the performance changes of TME during the epidemic period. At the same time, this paper also analyzes the profit point of TME group and put forward suggestions on its financial policy and business development.
\end{abstract}

Keywords: financial statements, mobile music, DuPont analysis, profitability, solvency

\section{INTRODUCTION}

China's mobile music market has undergone tremendous changes in the past decade. At first, users' awareness of paying was not high, and piracy was rampant. Then the National Copyright Administration issued the notice on ordering online music service providers to stop unauthorized dissemination of music works. Major music platforms gradually began to standardize their website and products, and users' awareness of paying gradually increased. At this time, the competition in the mobile music industry intensifies, and the elimination and integration go hand in hand. Tencent music has won most of the copyright very early relying on its abundant funds, occupying a large market share in the competitive market, it continued to grow even after the National Copyright Administration issued the notice [1]. In 2016, Netease cloud music won a place in the competitive industry relying on social networking. The development of mobile music follows the pace of the Internet development, after the development period, the standard period, and then enters the current mature and stable period. At present, the industry's head pattern is relatively stable. Tencent music group ranks first, followed by Netease cloud. These two companies occupy more than $90 \%$ of the mobile music market [2].

According to MobTech's research on mobile music industry, at present, $55 \%$ of the revenue of mobile music industry depends on user payment, including the purchase of membership, digital albums, etc.; $20 \%$ of the revenue comes from advertising, including open screen advertising, promotion space, etc.; $15 \%$ of the revenue comes from copyright operation, including copyright resale, distribution, etc.; $10 \%$ comes from other services, such as online shops that sell peripheral products, live broadcast, etc [3].

Financial statements can reflect the capital and profit status of an enterprise in a certain period of time, and then show the operation of the enterprise. It is observed that the performance of TME group, the leader of China mobile music industry, decreased during the epidemic period. This paper attempts to find out the problems by analyzing the information in its financial statements, and provide business ideas for the enterprise from the perspective of managers. This paper mainly analyzes the quarterly statements of TME group in recent years, calculates the quick ratio by analyzing its current assets and current liabilities, and evaluates the short-term solvency of the enterprise; evaluate the operating capacity of the enterprise by analyzing and calculating the turnover rate of current assets, the turnover rate of accounts receivable and the turnover rate of total assets; by calculating the enterprise's ROA, roe and profit data, evaluate the enterprise's profitability. At the same time, this paper uses DuPont analysis system to analyze what factors cause the change of roe, studies the development of mobile music market, and puts forward development suggestions according to the current situation of 
enterprises. This study applies the theoretical knowledge of financial statement analysis to practical research, enriches the practical application cases of financial statement analysis, and has a certain reference significance for the future development strategy of TME group.

\section{FINANCIAL STATEMENTS ANALYSIS}

Financial statements analysis is an essential way to understand a company's financial status. Generally speaking, we interpret the company's financial statements from three aspects: solvency, operating ability and profitability [4]. Next, this paper will analyze the financial statements of TME group from the above three aspects, and use DuPont analysis method to analyze which index changes caused the changes of net interest rate in the financial statements during the pandemic period in terms of profitability, so as to draw a conclusion on how to make the company obtain greater benefits from the perspective of enterprise managers.

\subsection{Solvency Ability Analysis}

Usually, we calculate short-term and long-term solvency indicators to measure the company's solvency [5]. In the short-term solvency index, we usually select the current ratio, quick ratio and cash ratio. As TME's inventory level is not high, there's little difference between TME's current assets and quick assets, only the current ratio and cash ratio are calculated here. It can be seen from Table 1 that TME's current ratio and cash ratio have a significant decline in the fourth quarter of 2019 , and then have a downward trend until the third quarter of 2020. Compared with the data from the third quarter of 2018 to the third quarter of 2019 , it can be ruled out that it is caused by the regular change of enterprise periodicity. But it is worth noting that even though TME's liquidity ratio and cash ratio have declined during COVID-19, its indicators remain at a very safe level.

Table 1. Important financial index indicated short-term solvency ability of TME

\begin{tabular}{|c|l|l|l|l|l|}
\hline & \multicolumn{1}{|c|}{2019 Q3 } & \multicolumn{1}{c|}{ 2019Q4 } & \multicolumn{1}{c|}{ 2020Q1 } & \multicolumn{1}{c|}{ 2020Q2 } & \multicolumn{1}{c|}{$2020 Q 3$} \\
\hline $\begin{array}{c}\text { Current } \\
\text { assets }\end{array}$ & $25,266,000,000$ & $26,914,000,000$ & $25,286,000,000$ & $25,611,000,000$ & $30,042,000,000$ \\
\hline Cash & $20,036,000,000$ & $15,426,000,000$ & $12,266,000,000$ & $11,776,000,000$ & $9,641,000,000$ \\
\hline Current debt & $7,632,000,000$ & $8,490,000,000$ & $8,003,000,000$ & $8,429,000,000$ & $8,622,000,000$ \\
\hline Current ratio & 3.31 & 3.17 & 3.16 & 3.04 & 3.48 \\
\hline Cash ratio & 2.63 & 1.82 & 1.53 & 1.40 & 1.12 \\
\hline
\end{tabular}

It can be seen from Table 2 that TME's asset liability ratio, equity ratio and equity multiplier have maintained a relatively stable level before the second quarter of 2020 and increased in the third quarter of 2020, which indicates that TME is increasing its financial leverage in the third quarter of 2020. Similarly, all indicators of TME are within the scope of safety, however, managers of companies may see it differently, I will elaborate this in the conclusion part of the essay.

We can conclude that the epidemic has a negative impact on TME's short-term solvency, but this impact is very small, TME still has a reliable short-term solvency. On the other hand, the pandemic has little impact on TME's long-term solvency.

Table 2. Important financial index indicated long-term solvency ability of TME

\begin{tabular}{|c|l|l|l|l|l|}
\hline & $2019 \mathrm{Q} 3$ & $2019 \mathrm{Q} 4$ & $2020 \mathrm{Q} 1$ & $2020 \mathrm{Q} 2$ & $2020 \mathrm{Q} 3$ \\
\hline Total assets & $49,941,000,000$ & $52,678,000,000$ & $52,456,000,000$ & $58,359,000,000$ & $64,069,000,000$ \\
\hline $\begin{array}{c}\text { Total liability } \\
\begin{array}{c}\text { Shareholders' } \\
\text { equity }\end{array}\end{array}$ & $8,306,000,000$ & $9,000,000,000$ & $8,502,000,000$ & $9,043,000,000$ & $14,624,000,000$ \\
\hline $\begin{array}{c}\text { Asset liability } \\
\text { ratio }\end{array}$ & 0.17 & $43,678,000,000$ & $43,954,000,000$ & $49,316,000,000$ & $49,445,000,000$ \\
\hline $\begin{array}{c}\text { Equity ratio } \\
\text { Equity }\end{array}$ & 0.20 & 0.17 & 0.16 & & 0.23 \\
\hline \begin{tabular}{c} 
multiplier \\
\hline
\end{tabular} & 1.20 & 1.21 & 0.19 & 0.18 & 0.30 \\
\hline
\end{tabular}


The high current ratio and cash ratio should have shown that the utilization efficiency of enterprise funds is not high, and the utilization of financial leverage is not high. However, during the pandemic period, the high current ratio, cash ratio and low asset liability ratio show that the enterprise has good solvency, which can effectively guarantee the safety of the enterprise's capital chain in the sudden black swan event. But at the same time, it can remind the company managers that they can consider increasing the financial leverage under the condition of predicting the future economics' promising situation. On the one hand, Tencent music is in the dominant position in the industry, on the other hand, Tencent music relies on Tencent group's own strong financial resources, whether it is promotion resources or talent resources are very rich, which can greatly enhance the protection of Tencent music, so the author thinks that managers can make some bold moves in finance.

\subsection{Operating capacity analysis}

Operating capacity is the financial ratio to measure the efficiency of enterprise asset management. It can be

Table 3. Important financial index indicated operating capacity of TME

\begin{tabular}{|c|c|c|c|c|c|}
\hline & 2019 Q3 & $2019 Q 4$ & $2020 Q 1$ & 2020Q2 & $2020 Q 3$ \\
\hline $\begin{array}{l}\text { Days of inventory } \\
\text { turnover(days) }\end{array}$ & 0.76 & 0.66 & 0.54 & 0.55 & 0.48 \\
\hline $\begin{array}{c}\text { Inventory } \\
\text { turnover(times) }\end{array}$ & 356.9 & 549.54 & 166.69 & 324.86 & 557.37 \\
\hline $\begin{array}{c}\text { Days sales } \\
\text { outstanding(days) }\end{array}$ & 23.94 & 26.05 & 30.53 & 28.46 & 28.27 \\
\hline $\begin{array}{c}\text { Accounts receivable } \\
\text { turnover(times) }\end{array}$ & 11.28 & 13.82 & 2.95 & 6.33 & 9.55 \\
\hline $\begin{array}{l}\text { Turnover of current } \\
\text { assets(times) }\end{array}$ & 0.79 & 1.07 & 0.24 & 0.5 & 0.73 \\
\hline $\begin{array}{c}\text { Turnover rate of fixed } \\
\text { assets(times) }\end{array}$ & 109.95 & 146.59 & 36.06 & 74.19 & 116.96 \\
\hline $\begin{array}{l}\text { Turnover of total } \\
\text { assets(times) }\end{array}$ & 0.38 & 0.52 & 0.12 & 0.24 & 0.36 \\
\hline
\end{tabular}

In terms of operating capacity, although the financial statements show that TME's operating capacity has decreased significantly during the epidemic period, the author believes that managers of enterprises need not worry too much about similar problems. One reason is the need to consider the particularity of China during the COVID-19 era. China's government adopted strict management and control measures during the fight against COVID-19, including temporary isolation measures for various cities in Hubei Province, and other provinces and regions also strictly controlled entry and seen from Table 3 that although the inventory turnover rate decreased in the first quarter of 2020, from the perspective of inventory turnover days, TME's inventory turnover was less affected by the pandemic. Combined with the turnover rate of accounts receivable, current assets, fixed assets and total assets, these indicators tend to get better from the third quarter to the fourth quarter of 2019 , but they declined significantly in the first quarter of 2020. It can be seen that under the influence of the epidemic, TME's operating capacity has declined correspondingly. However, due to the strong financial support of the enterprise itself, the ability to resist such emergencies is also strong. Even if the operation capacity is impacted temporarily due to the epidemic, the enterprise can recover quickly. It can be seen that all the data indicating the operating capacity of enterprises have a better trend in 2020 , which indicates that the liquidity of enterprises has not been seriously impacted by the pandemic. exit, which objectively reduced the mobility of personnel and delayed the resumption of many enterprises' production. Therefore, not only is the TME group, most enterprises have similar problems, this is the particularity of COVID-19 period rather than the enterprise itself. Another reason is that our observation shows that the indicators of TME's operating capacity show that the operating capacity of enterprises tends to increase before and after the pandemic, which further shows that the current financial policy of enterprises is conducive to enhancing the operating capacity of enterprises. To sum 
up, the author believes that enterprise managers need not worry too much about the problem of enterprise operation ability, maintaining the current fiscal policy can deal with similar emergencies.

\subsection{Profitability analysis}

It can be seen from Table 4 that TME's net operating rate, net interest rate of total assets and net interest rate of equity change almost in the same direction. Figure 1 shows that from the fourth quarter of 2019 to the first quarter of 2020, that is, when the pandemic situation is the most serious in China, these three indicators all decrease significantly, but then gradually turn better. Earnings per share and the previous indicators have a similar trend [6].

Table 4. Important financial index indicated profitability of TME

\begin{tabular}{|c|l|l|l|l|l|}
\hline & \multicolumn{1}{|c|}{$2019 \mathrm{Q} 3$} & \multicolumn{1}{|c|}{$2019 \mathrm{Q} 4$} & \multicolumn{1}{c|}{ 2020Q1 } & 2020Q2 & $2020 \mathrm{Q3}$ \\
\hline $\begin{array}{c}\text { net profit } \\
\text { margin on } \\
\text { sales(\%) }\end{array}$ & $16.19 \%$ & $15.64 \%$ & $14.04 \%$ & $13.81 \%$ & $14.24 \%$ \\
\hline $\begin{array}{c}\text { return on } \\
\text { assets(\%) }\end{array}$ & $5.88 \%$ & $7.55 \%$ & $1.69 \%$ & $3.13 \%$ & $4.63 \%$ \\
\hline $\begin{array}{c}\text { return on } \\
\text { equity(\%) }\end{array}$ & $7.38 \%$ & $9.81 \%$ & $2.01 \%$ & $3.92 \%$ & $6.64 \%$ \\
\hline $\begin{array}{c}\text { earnings per } \\
\text { share }\end{array}$ & 11.09 & 15.16 & 3.76 & 7.89 & 12.41 \\
\hline
\end{tabular}

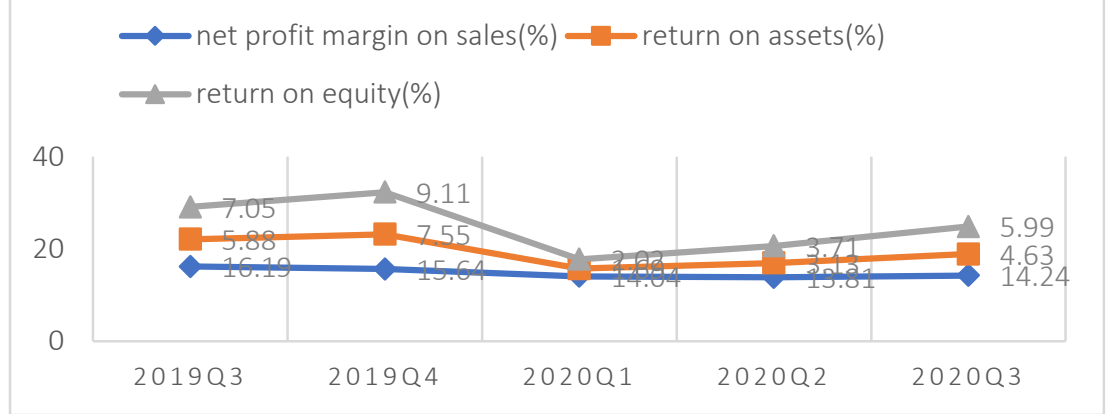

Figure 1. Important financial index indicated profitability change of TME

From TME's seasonal reports, we calculate its key profitability indexes, and find out that TME's return on equity dropped from $9.81 \%$ to $2.01 \%$, we shall apply DuPont analysis method to find out what contribute to ROE's drop in the pandemic period.

DuPont analysis method breaks ROE into three index, net profit margin on sales, return on assets and return on equity [7].

$$
\begin{gathered}
\mathrm{ROE}=\frac{\text { net profit }}{\text { revenues }} \times \frac{\text { revenues }}{\text { total assets }} \times \frac{\text { total assets }}{\text { shareholders' equity }} \\
\begin{aligned}
\mathrm{ROE}=\text { net } \text { profit } & \text { margin on sales } \\
& \times \text { turnover of total assets } \\
& \times \text { equity multiplier }
\end{aligned}
\end{gathered}
$$

So in the forth quarter of 2019, TME's return on equity is $9.81 \%=15.64 \% * 0.52 * 1.21$. In the first quarter of 2020 , TME's return on equity is $2.01 \%=14.04 \%$ * $0.12 * 1.19$.

Impact of operating net interest rate on roe: $(14.04 \%$ $-15.64 \%) * 0.52 * 1.21=-1.01 \%$

The impact of total asset turnover on roe: $14.04 \% *$ $(0.12-0.52) * 1.21=-6.80 \%$

Impact of equity multiplier on roe: $14.04 \% * 0.12 *$ $(1.19-1.21)=-0.03 \%$ 
From the results of DuPont analysis, the decrease of ROE is mainly due to the impact of the decrease of total asset turnover. Although the operating net interest rate has declined, it has little impact. Therefore, the decrease of ROE of TME during the epidemic period is mainly due to the decrease of sales results and asset operation ability of enterprises during the epidemic period, and there is no serious problem in sales.

\subsection{Profit point}

According to the quarterly reports disclosed by TME in recent quarters, the revenue of social entertainment services and other services accounts for about $70 \%$ of the total profit, which is almost twice that of traditional online music services. Table 5 lists TME's revenue from online music services and others, it can be seen that the main revenue of TME group still comes from derivative entertainment services based on music copyright.

Table 5. Financial profit composition of TME

\begin{tabular}{|l|l|l|l|l|l|}
\hline \multicolumn{7}{|c|}{ Profit composition } \\
\hline $\begin{array}{l}\text { Revenues (RMB, in millions, except } \\
\text { per share data) }\end{array}$ & 2019 Q3 & 2019 Q4 & $2020 Q 1$ & $2020 Q 2$ & $2020 Q 3$ \\
\hline Online music services & $1,846.00$ & $2,139.00$ & $2,044.00$ & $2,221.00$ & $2,324.00$ \\
\hline $\begin{array}{l}\text { Social entertainment services and } \\
\text { others }\end{array}$ & $4,661.00$ & $5,154.00$ & $4,267.00$ & $4,711.00$ & $5,251.00$ \\
\hline $\begin{array}{l}\text { Proportion of revenue generated by } \\
\text { social entertainment services }\end{array}$ & $71.63 \%$ & $70.67 \%$ & $67.61 \%$ & $67.96 \%$ & $69.32 \%$ \\
\hline
\end{tabular}

Compared with other music streaming media platforms, TME's profit points lie in two points. First, a large number of copyrights can provide the basis for its traditional online music services. Second, the extensive and innovative music based social entertainment has a large number of users and creates considerable income for enterprises. At the same time, there is a good synergy between online music and social entertainment business. Enterprises benefit from this virtuous circle and consolidate TME's leading position in the mobile music market.

From the quarterly report, TME plans to invest in product innovation since 2019 to further expand the user base and improve user participation. These measures include introducing short videos into music streaming media pages, increasing online live performances, and developing new playing methods of its music entertainment software, such as We Sing and Kugoo Singing, so as to attract more users. These entertainment services derived from traditional online music services are also important businesses that distinguish TME from other companies in the industry. This also shows from another aspect that TME group clearly recognizes that its profit point lies in these derived social entertainment services. Investing more time and energy in these services in the future will bring greater benefits to the enterprise.

\section{PREDICTION AND SUGGESTIONS}

\subsection{Prediction of future mobile music market}

With the implementation of China's 2021 new copyright regulations, the situation of exclusive copyright in the future music streaming media market will also be reduced, and the exclusive cooperation between the copyright owner and the platform will be clearly limited. What follows is that musicians will bid farewell to the high price expectation, that is, in the past, the platform often paid a price far exceeding the saleable price in order to win the exclusive copyright of some super musicians or music programs. With the implementation of the new regulations, these high premiums will gradually disappear. In other words, the copyright settlement will be the first mock exam of the actual usage. After the unification of the mode, the whole music streaming media industry will become more transparent. The platform side will no longer need to pay a high premium to buy exclusive copyright in the purchase of copyright, and the corresponding cost will also be reduced.

In the past few years, when the exclusive copyright has not been banned, TME group has occupied most of the "core copyright" with strong early rising funds and keen insight, and vigorously developed social entertainment services with high profit space with these core copyrights. According to the financial statements of TME group in the first quarter of 2021, the scale of TME music library is more than 60 million, and more than 200000 independent musicians have signed contracts; According to the prospectus of Netease cloud Music Hong Kong stock exchange, the Netease cloud music library, one of the competitors of TME group, also exceeded 60 million, and more than 230000 independent musicians were signed. Although from the data, TME and other mobile music media companies have almost the same volume of music libraries, because most of the 
songs with exclusive copyright owned by TME group belong to the core music library, that is, the popular songs that users often listen to, TME group has opened a wider range of users with this advantage [8]. On this basis, it took the lead in developing social entertainment services such as We Sing. After opening the copyright, Netease cloud music still faces the problems of slow financing and IPO process, huge cost of purchasing the copyright of popular music library, and far behind TME in terms of social entertainment services. Therefore, in the foreseeable future, Tencent music will still occupy the head position in the mobile music market, and its position is difficult to be shaken.

\subsection{Financial advice to TME group}

Based on the above analysis of TME group's financial statements in recent quarters, we can find that TME's financial situation is very stable. According to DuPont's analysis, the decline in performance during the epidemic period is mainly due to the reduction of total capital turnover, not sales. In fact, it can also be seen from the key operating indicators in the TME financial statements that online music and social entertainment services remained highly active during the epidemic, and there was an upward trend. According to the characteristics of TME group's financial statements, the financial suggestions are as follows: 1. Maintain the existing financial policy. The existing covid-19 fiscal policy and ownership structure have proved to be able to withstand emergencies such as the new crown epidemic and can make enterprises stable and profitable. Maintaining the existing fiscal policy is a wise choice for the steady development of enterprises. 2. Appropriately invest more company resources and energy into social entertainment services. According to the profit point analysis in the second part, about $70 \%$ of the profits are created by social entertainment services. At the same time, according to TME's financial statements, TME is developing live broadcasting services for social entertainment services, entering the long format audio market and expanding a broader audio entertainment space. This is a very good strategy. With the saturation of traditional online music services, innovation in more profitable audio entertainment services can undoubtedly help enterprises make profits and help enterprises occupy a higher market share in the undeveloped audio entertainment industry.

\subsection{Suggestions on TME group's future business development}

The first suggestion is to improve the training and support plan for original music creators. In the future mobile music market, the threshold for the copyright of popular songs in the past will gradually disappear under the influence of policies, and the differences between Tencent music and other companies' online music libraries will gradually narrow. Under such a trend,
Tencent music should proactively cultivate music creators with higher stickiness with the platform, enrich the music library and create musicians of its own brand. Meanwhile, Tencent music can also establish music support plans or create singing competitions to attract excellent original musicians for in-depth cooperation with better cooperation terms. In the future, Tencent music can launch online performances, radio story sharing, song comment area, singer community airborne interaction and other activities with deeply cooperative musicians to increase the stickiness between music fans and the platform.

The second suggestion is to optimize the newly developed social entertainment services while improving the existing social entertainment services. Since TME group has taken the lead in music based derivative social entertainment services, it is very meaningful for TME to seize this opportunity. From the results of the experimental TME live launched by TME, the form of offline concert plus paid online live broadcast has received high praise, especially during the epidemic. With the gradual improvement of the epidemic situation in China and the gradual recovery of offline performances, does TME live still need to be retained? The author thinks this form can be retained, but the performance frequency can be reduced appropriately. Because even if offline performances are gradually restored, some users will still be unable to see offline performances due to time and space constraints, and the form of online live broadcasting can take care of this part of users. In addition, the global epidemic is not completely over yet. TME can also cooperate with excellent musicians overseas to let Chinese audiences enjoy different music. For the audio reading service that TME is planning to launch, the author thinks more energy needs to be invested, because the competitors in this part are no longer Netease cloud music faced by traditional online music services. There are already pioneers such as Easy Listening in this field. How to break the homogenization of service content is a problem that Tencent music needs to think about.

\section{CONCLUSION}

Through above analysis, the performance decline of TME group during the epidemic period is mainly due to the decline of total asset turnover, not sales problems. However, under the general environment of the epidemic, this is an inevitable result, but this impact is short-lived. TME's main source of revenue is derived entertainment services based on music copyright, which is one of its differences from other companies in the industry. At the same time, TME is in a leading position in this sector and has great advantages. On the basis of maintaining the existing financial policy, TME group can pay more attention to the development of music derived 
entertainment services, expand business segments and maximize corporate profits.

\section{AUTHORS' CONTRIBUTIONS} Chen.

This paper is independently completed by Qianyue

\section{ACKNOWLEDGMENTS}

I would like to thank my teacher Xian Sun for enlightening me with the knowledge of business and accounting taught in the winter vacation project. Thank teacher Elaine for taking the trouble to answer my questions and inspire my writing ideas. At the same time, I also thank my parents for their support and encouragement during my writing.

\section{REFERENCES}

[1] Shen Xiaobai et al. Digital online music in China - A "laboratory" for business experiment [J] Technological Forecasting \& Social Change, 2019, $139: 235-249$.

[2] Tencent Music Entertainment Group; Tencent Music Completed Investment in Radio Music, a Leading Music-for-business Provider in China [J] Internet Weekly News, 2020: 21-47.

[3]MobTech, http://www.199it.com/archives/1170569.html, 2020.12

[4] Bingxuan Li. Analysis of Financial Statements of M\&A Enterprises from the Perspective of Investor-Case Study based on Wanda Film Acquiring Muwei Fashion [A] Institute of Management Science and Industrial Engineering. Proceedings of the First International Symposium on Economics, Management, and Sustainable Development (EMSD 2019) [C] Institute of Management Science and Industrial Engineering: Computer Science and Electronic Technology International Society, 2019:11.

[5] Marina Proklin and Jasna Zima. Impact of liquidity and solvency on business operations of companies [J] Economic Journal, 2011.

[6] Tencent music entertainment group seasonal financial reports, 2020 (4). https://ir.tencentmusic.com/financial-Results

[7] Jiayi Tai, Qi Cao. Analysis of financial statements in the express delivery industry [A] Institute of Management Science and Industrial Engineering. Proceedings of 2019 International Conference on Global Economy and Business Management (GEBM 2019) [C] Institute of Management Science and Industrial Engineering: Computer Science and Electronic Technology International Society, 2019: 7.

[8] Hexun, Tencent music has no exclusive copyright. Can online music "change?", 2020 (7) https://baijiahao.baidu.com/s?id=17062397626500 $43829 \& w f r=$ spider\&for $=$ pc. 